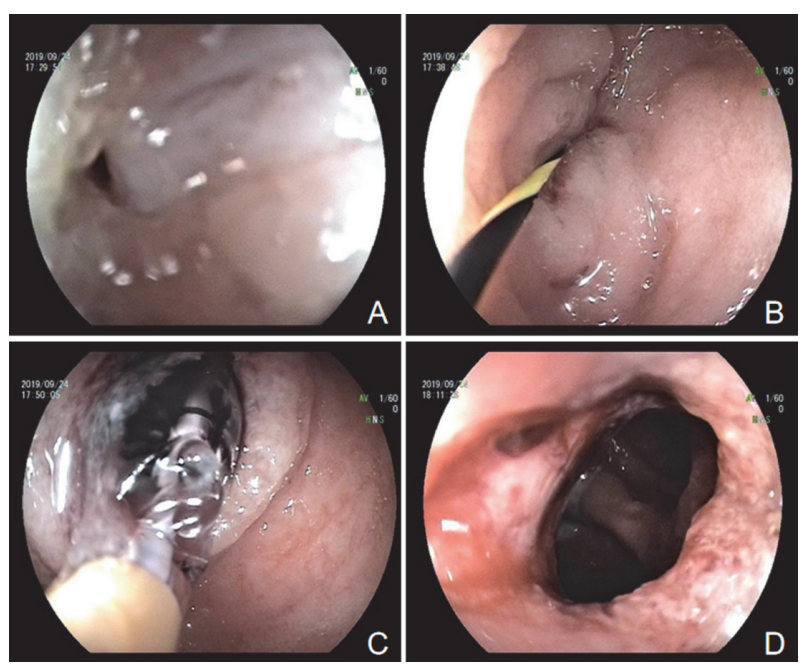

Abstract IDDF2021-ABS-0016 Figure 1

stenosis in the future. Pre-endoscopic treatment for AIS has high safety and definite short-term efficacy, which can improve the prognosis and the quality of life of patients. The longterm effect needs to be further followed up.

\section{IDDF2021-ABS-0017 DEVELOPMENT AND VALIDATION OF A NEW ALGORITHM MODEL FOR DIFFERENTIAL DIAGNOSIS BETWEEN CROHN'S DISEASE AND INTESTINAL TUBERCULOSIS}

Yi Lu*, Jiayin Yao, Min Zhi. The Sixth Affiliated Hospital, Sun Yat-sen University, China

\subsection{6/gutjnl-2021-IDDF.107}

Background Sometimes it was a great challenge to distinguish Crohn's disease (CD) and intestinal tuberculosis (ITB); we conducted this study was to identify a simple and useful algorithm for distinguishing them.

Methods We retrospectively reviewed the medical history of the patients who were diagnosed as ITB or CD. We firstly identified ITB patients, and then the patients diagnosed with CD were matched by age, sex, and admission time in a 1:1 ratio. Patients who were admitted between May 1, 2013 and April 30, 2019 were regarded as training cohort, and patients admitted between May 1, 2019 and May 1, 2020 were regarded as validation cohort. We used multivariate analysis to identify the potential variables, and then we used $\mathrm{R}$ package part to build the classification and regression tree (CART), and validated the newly developed model.

Results In total, the training cohort included 84 ITB and 84 CD patients, and the validation cohort included 22 ITB and $22 \mathrm{CD}$ patients. Multivariate analysis showed that positive TSPOT, $\geq 4$ segments involved, longitudinal ulcer, circular ulcer, and aphthous ulcer, were confirmed as independent discriminating factors. Using these parameters to build the CART model made an overall accuracy rate was $88.64 \%$, with sensitivity, specificity, NPV, and PPV being 90.91\%, 86.36\%, $90.48 \%$, and $86.96 \%$, respectively.

Conclusions We developed a simple and novel algorithm model covering laboratory, imaging, and endoscopy parameters with CART to differentiate ITB and CD with good accuracy.

\section{IDDF2021-ABS-0020 A SURVIVAL ANALYSIS OF CHINESE PATIENTS WITH GASTROINTESTINAL MUCOSAL MELANOMAS: A SINGLE- CENTER RETROSPECTIVE STUDY}

Junrong Chen*, Jiachen Sun, Jiayao Huang. The Sixth Affiliated Hospital, Sun Yat-sen University, China

\subsection{6/gutjnl-2021-IDDF.108}

Background Mucosal melanomas are highly malignant tumors, while are of great interest due to their aggressive behavior and less favorable prognosis, which could be the result of many reasons, for example, late diagnosis, patients' delay and the obscured anatomic site of origin. We, in this paper, do a retrospective study to investigate the characteristics and prognosis of gastrointestinal mucosal melanomas in a Chinese population to help future clinic doctors to recognize the prognosis of the disease.

Methods We retrospectively studied 49 patients diagnosed with gastrointestinal mucosal melanomas. Multivariate analyses of

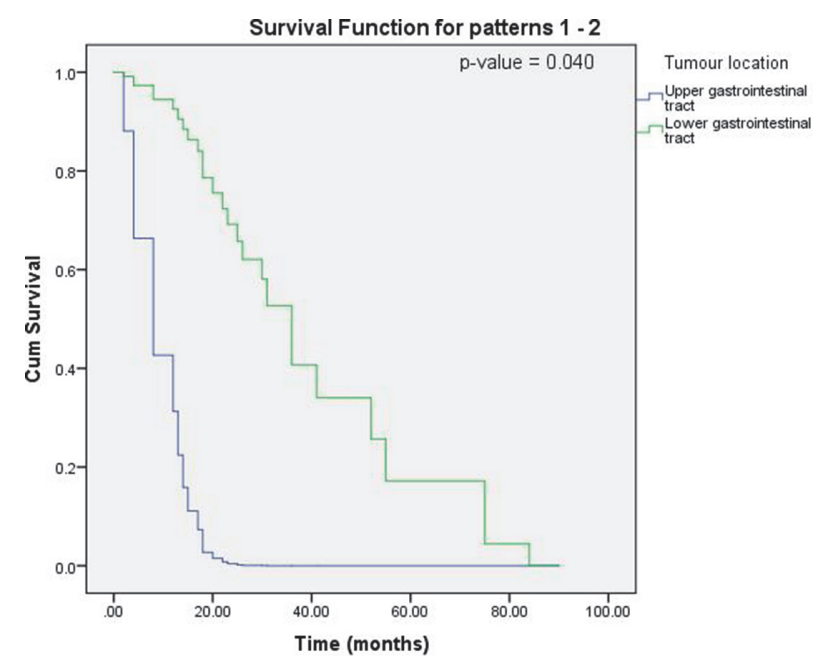

Abstract IDDF2021-ABS-0020 Figure 1

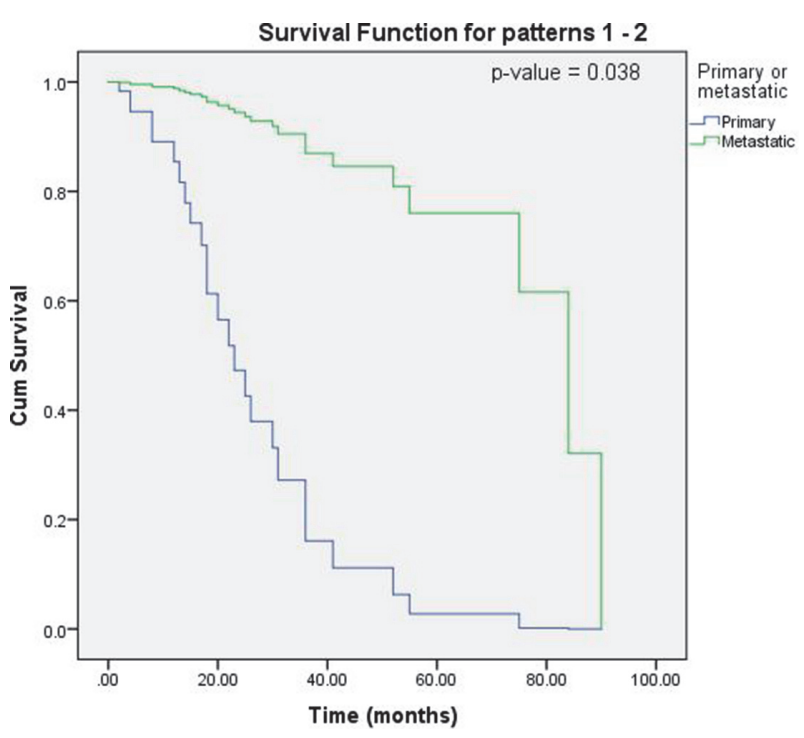

Abstract IDDF2021-ABS-0020 Figure 2 
prognosis and the overall survival (OS) were performed using the Cox proportional hazard model.

Results Multivariate analyses show that the number of the lesions ( $\mathrm{P}=0.006$, IDDF2021-ABS-0020 Figure 1. OS curves according to tumour location (Cox proportional hazards model)), the lymph nodes metastasis $(\mathrm{P}<0.001$, IDDF2021ABS-0020 Figure 2. OS curves according to tumour type (primary or metastatic) (Cox proportional hazards model)), the overall treatments $(\mathrm{P}=0.020)$, and the surgery $(\mathrm{P}=0.025)$ are the independent factors that may affect the prognosis of patients with gastrointestinal mucosal melanomas. What's more, this is a rare study to analyze the association between the certain expression of immunohistochemical indexes and the OS of patients with gastrointestinal mucosal melanomas. However, we did not find it significantly associated with the OS of our patients. All the results shown above need further exploration.

Conclusions The condition of primary or metastatic tumors, the anatomic sites in the gastrointestinal tract, and the lymph nodes metastasis may be the independent factors that affect the prognosis of patients with gastrointestinal mucosal melanomas. This study is expected to provide some clues for future exploration which will help clinicians improve the accuracy of judging prognosis.

\section{IDDF2021-ABS-0021 BETTER BOWEL PREPARATION - APPROPRIATE PREOPERATIVE TIME AND GRAPHIC GUIDANCE TO STRENGTHEN EDUCATION BEFORE EXAM}

Jiachen Sun*, Jiancong Hu, Yongpeng Chen. The Sixth Affiliated Hospital, Sun Yat-sen University, China

\subsection{6/gutjnl-2021-IDDF.109}

Background Inadequate bowel preparation (BP) was considered as a major obstacle for successful colonoscopy, which leads to the lower rate of adenoma and polyp detection, increasing related costs, lower cecal intubation rate, and the possibility of repeated examination. We performed a secondary analysis of a colorectal cancer screening program to explore the factors which could improve the bowel preparation quality before colonoscopy.

Methods 738 patients were included in this study. Divided into graphic group $(n=242)$ and word group $(n=496)$, according to their education of BP, and 6-8 hours (group 1, $\mathrm{n}=106$ ), 9-12 hours (group 2, $\mathrm{n}=228$ ) and 13-17 hours (Group 3, $\mathrm{n}=402$ ) according to the interval between BP and colonoscopy. All patients were scored BP according to the BBPS score during the exam.

Results The BP of graphic group was significantly better than that of word group $(P<0.001)$. The score of BP of the Group 1 and Group 2 were both significantly higher than that of Group $3(P<0.001)$. After adjustment, the score of BP of the Group 1 and Group 2 were still both significantly higher $(P=0.012$ and $P=0.032)$ (IDDF2021-ABS-0021 Figure A. The relationship between BBPS and interval time of nonadjustment B) (IDDF2021-ABS-0021 Figure B. The relationship between BBPS and interval time after adjustment for gender, age, smoking history, drinking history, family history of colorectal cancer, family history of cancer, type of laxatives, education methods).

Conclusions Patients who use graphic version of the education manual were getting better bowel preparation and the BP is better starting in 6-12 hours and best in 6.5 hours before the exam.

\section{IDDF2021-ABS-0023 EFFECTIVITY OF MOIST EXPOSED BURN OINTMENT (MEBO) AND THE ROLE ON REDUCING THE CHEMOTHERAPY INTERRUPTION OF CAPECITABINE ASSOCIATED HAND FOOT SYNDROME ON STAGE III COLORECTAL ADENOCARCINOMA}

${ }^{1}$ Budhi Ida Bagus*, ${ }^{2}$ Agustriani Nunik, ${ }^{3}$ Ermawan Rieva, ${ }^{2}$ Suwardi Suwardi, ${ }^{4}$ Sungkar Amru, ${ }^{5}$ Saadhi Ikhdin R, ${ }^{6}$ Mastini Ida Ayu Kade, ${ }^{1}$ Metria Ida Bagus, ${ }^{7}$ Setyawati Ida Ayu. ${ }^{1}$ Department of Surgery, Sebelas Maret University, Indonesia; ${ }^{2}$ Pediatric Surgery Department, Sebelas Maret University, Indonesia; ${ }^{3}$ Orthopaedic Surgery Department, Sebelas Maret University, Indonesia; ${ }^{4}$ Plastic Surgery Department, Sebelas Maret University, Indonesia; ${ }^{5}$ Department of Surgeny, Moewardi General Hospital, Indonesia; ${ }^{6}$ Clinical Pharmacy Department, Moewardi General Hospital, Indonesia; ${ }^{7}$ Medical Faculty, Pendidikan Ganesha University, Indonesia

\subsection{6/gutjpl-2021-IDDF.110}

Background A common adverse effect of the fluoropyrimidine chemotherapy agent capecitabine is Hand-foot syndrome (HFS), known as a palmoplantar erythrodysesthesia. Hand-foot syndrome of any grade is reported to affect $43 \%$ to $71 \%$ of patients treated with single-agent capecitabine chemotherapy.
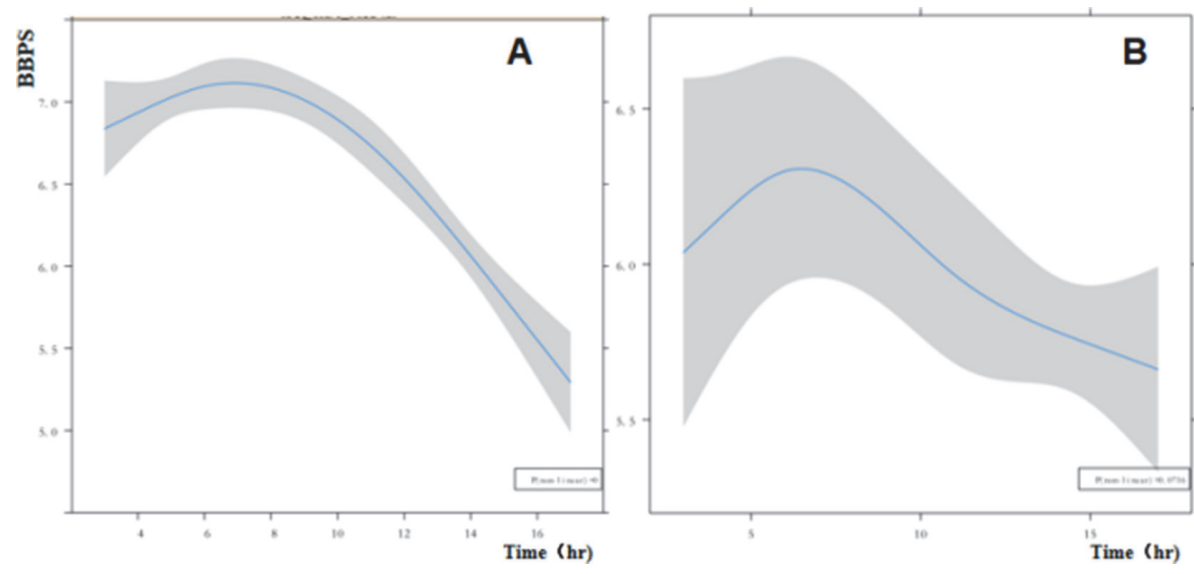